\title{
Mediterranean diet and cognitive decline
}

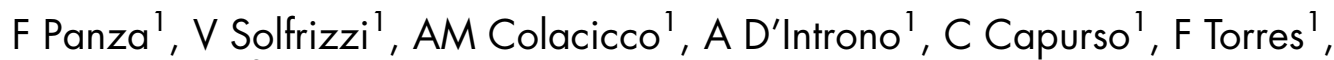 \\ A Del Parigi ${ }^{1,2}, S$ Capurso $^{1}$ and A Capurso ${ }^{1, *}$ \\ ${ }^{1}$ Department of Geriatrics, Center for Aging Brain, Memory Unit, University of Bari, Policlinico, Piazza Giulio Cesare \\ 1 1, I-70124 Bari, Italy: ${ }^{2}$ National Institutes of Health, National Institute of Diabetes, Digestive, and Kidney Diseases, \\ Phoenix, AZ, USA
}

\begin{abstract}
Objective: To investigate the possible role of diet in age-related cognitive decline (ARCD) and cognitive impairment of both degenerative (Alzheimer's disease, AD) and vascular (vascular dementia, VaD) origin.

Design: Literature review.

Results: In an elderly population of southern Italy with a typical Mediterranean diet, high energy intake of monounsaturated fatty acids (MUFA) appeared to be associated with a high level of protection against ARCD. In addition, dietary fat and energy in the elderly seem to be risk factors, while fish consumption and cereals are found to reduce the prevalence of $\mathrm{AD}$ in European and North American countries. Finally, the relative risk of dementia ( $\mathrm{AD}$ and $\mathrm{VaD}$ ) was lower in the subjects of a French cohort who drank three or four glasses of red wine each day compared with total abstainers. Conclusion: Essential components of the Mediterranean diet - MUFA, cereals and wine - seem to be protective against cognitive decline. As such, dietary antioxidants and supplements, specific macronutrients of the Mediterranean diet, oestrogens and anti-inflammatory drugs may act synergistically with other protective factors, opening up new therapeutic interventions for cognitive decline.
\end{abstract}

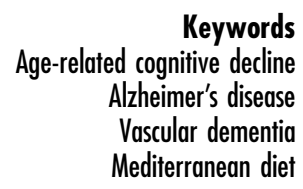

Cognitive impairment is a major component of dementia syndromes and influences the individual's ability to function independently. Due to ageing of the population, the prevalence of cognitive impairment is expected to increase. Different diagnostic criteria have been proposed to distinguish individuals with mild cognitive disorders associated with ageing from non-affected individuals, and one of the best established of these classifications is age-associated memory impairment (AAMI $^{1}$. AAMI, however, is generally non-progressive and is thus more likely to be a phenomenon of normal ageing $^{2,3}$. The terms 'age-related cognitive decline' (ARCD) and 'ageing-associated cognitive decline' have recently been proposed ${ }^{4,5}$ to indicate an objective decline in cognitive functioning associated with the ageing process but within normal limits given the person's age. Whether ARCD is the expression of a normal ageing process, or represents a distinct clinical entity or, eventually, a continuum with dementia, is still difficult to establish ${ }^{2,6}$. In fact, recent results from longitudinal studies suggest that the subgroup at high risk for developing dementia may be identified by using a more detailed procedure for the assessment of cognitive decline than those listed in the AAMI criteria. In effect, a high incidence (45\%) of dementia was found in individuals aged $>75$ years who were diagnosed as having 'minimal dementia' by the CAMDEX interview ${ }^{7}$. Furthermore, $44 \%$ of patients aged between 73 and 85 years, identified as having 'mild cognitive impairment' according to Clinical Dementia Rating scale, developed dementia within 3 years ${ }^{8}$.

The causes of ARCD are unknown, but some studies have suggested that it may be prevented ${ }^{\text {. Cardiovas- }}$ cular and other chronic diseases ${ }^{10,11}$, hypertension ${ }^{12}$, diabetes mellitus ${ }^{13}$, depression ${ }^{14}$ and low levels of physical activity have been identified as risk factors for $\mathrm{ARCD}^{15}$. On the contrary, high socio-economic status, a flexible personality in middle age and the maintenance of vision and hearing have been identified as protective factors against $\mathrm{ARCD}^{16}$. The role of diet in ARCD has not been extensively investigated. Deficiencies of micronutrients (vitamins $\mathrm{B}_{1}, \mathrm{~B}_{2}, \mathrm{~B}_{6}, \mathrm{~B}_{12}$ and $\mathrm{C}$ and folate) have been described quite frequently in elderly people and found to be significantly associated with cognitive impairment ${ }^{17,18}$. On the other hand, very few data are available on the role of macronutrient intake in $\mathrm{ARCD}^{19}$.

In the 1950 s and 60s, Keys' studies found the typical dietary pattern of the Greek island of Crete to be associated with especially good health, and this pattern has come to be viewed as the model Mediterranean diet. This model has been extended to include diets consumed in olive-producing Mediterranean regions, because olive oil was a principal source of fat in the Cretan diet. Therefore, the trivial term 'Mediterranean diet' is used to refer to dietary patterns similar to those of Crete in the 
early 1960 s and other regions in the Mediterranean where olive oil is a major fat source ${ }^{20}$.

\section{Mediterranean diet and age-related cognitive decline}

In a recent study, we investigated the relationships between dietary macronutrient intakes and age-related changes in cognitive functions in southern Italy, a region with the typical Mediterranean dietary pattern ${ }^{21-23}$. The subjects of this study were part of a larger study, the Italian Longitudinal Study on Aging, promoted by the Italian National Research Council-Targeted Project on Aging, with a sample of 5632 subjects aged 65-84 years, freeliving or institutionalised ${ }^{22}$.

In this study, a standardised test battery assessing global cognitive functions (Mini Mental State Examination, MMSE), selective attention (Digit Cancellation Test, DCT) and episodic memory (Babcock Story Recall Test), and a semi-quantitative food-frequency questionnaire evaluating macronutrient energy intakes, was performed on 278 non-demented elderly subjects from the randomised cohort of Casamassima, Bari $(n=704)$.

Results showed an inverse relationship between energy intake from monounsaturated fatty acids (MUFA) and cognitive decline (MMSE $<24$ ). The effect of education on the odds of having an MMSE score $<24$ decreased exponentially with the increase of MUFA intake ( $>2400 \mathrm{~kJ} \mathrm{day}^{-1}$ : odds ratio, 0.69). Moreover, a significant inverse association was observed between MUFA intakes and DCT score (odds ratio, 0.99). No association was found between nutritional variables and episodic memory (Table 1). These findings appear to be consistent with other studies, and indicate an association between dietary intakes and cognitive functions. In a recent longitudinal study of a well-nourished and cognitively unimpaired sample of elderly community residents, a significant association between protein intakes and cognitive performances was found ${ }^{24}$. In another study, a significant association between functional variables (i.e. activities of daily living) and alcohol intake was found, probably in relation to a better health status of moderate alcohol

Table 1 Change in the odds ratio (OR) and 95\% confidence interval $(\mathrm{Cl})$ for cognitive decline, as assessed by Mini Mental State Examination (MMSE) score $<24$, with energy intake from monounsaturated fatty acids (MUFA), controlling for education and age. Italian Longitudinal Study on Aging-Casamassima, first prevalence survey, 1992-1993 (modified from Solfrizzi et al. ${ }^{22}$ )

\begin{tabular}{lccccc}
\hline & \multicolumn{2}{c}{$\begin{array}{c}\text { Adjusted } \\
\text { for education }\end{array}$} & & \multicolumn{2}{c}{$\begin{array}{c}\text { Adjusted for } \\
\text { education and age }\end{array}$} \\
\cline { 2 - 3 } $\begin{array}{l}\text { MUFA intake } \\
\left.\mathrm{kJ} \mathrm{day}^{-1}\right)\end{array}$ & OR & $95 \% \mathrm{Cl}$ & & OR & $95 \% \mathrm{Cl}$ \\
\hline$\leq 800$ & 33.0 & $8.2-133$ & & 37.5 & $9-156$ \\
$801-1200$ & 14.9 & $6.2-35.8$ & & 16.9 & $6.7-42.7$ \\
$1201-1600$ & 6.7 & $3.7-12$ & & 7.6 & $3.9-14.6$ \\
$1601-2000$ & 3.0 & $1.3-6.7$ & & 3.4 & $1.4-8$ \\
$2001-2400$ & 1.3 & $0.4-4.9$ & & 1.5 & $0.4-5.8$ \\
$2401-2800$ & 0.6 & $0.1-4.5$ & & 0.7 & $0.1-4.5$ \\
\hline
\end{tabular}

consumers $^{25}$. Finally, non-institutionalised elderly subjects with the best performance in cognitive tests had lower intakes of MUFA, saturated fatty acids (SFA) and cholesterol, and higher intakes of total food, fruit, carbohydrate, thiamin, folate and vitamin $\mathrm{C}^{26}$. These apparently conflicting results could be due in part to some methodological differences in food-frequency questionnaires and selection of participants, which was not performed randomly, but within three elderly persons' clubs.

Due to the dietary pattern of our population, the typical Mediterranean diet and the rural setting of the study (Casamassima), the mean consumption of olive oil was particularly high: $46 \mathrm{~g} \mathrm{day}^{-1}$ (range $12.6-113.1 \mathrm{~g} \mathrm{day}^{-1}$ ). MUFA as percentage of total energy intake was $17.6 \%$, of which $85 \%$ was derived from olive oil. It cannot be excluded that the positive effect of dietary habits on cognitive functioning among healthy elderly subjects could be due in part to the antioxidant compounds of olive oil, i.e. tocopherols and polyphenols. In fact, some pathological conditions, which can be triggered to some extent by an uncontrolled production of free radicals, could probably be prevented or retarded with high intakes of dietary antioxidants (i.e. vitamins $\mathrm{A}, \mathrm{E}$ and $\mathrm{C}$ and carotenes) that might yield beneficial effects on frontal/ subcortical brain systems, with cognitive functions that might be enhanced (increased performance on effortful memory tasks) $)^{27-29}$. However, the antioxidant activity of dietary macronutrients has not been found to exert a protective effect on age-related changes in cognitive function in every circumstance. In fact, in a Japanese population study ${ }^{16}$, high dietary intake of antioxidant compounds was significantly associated with Alzheimer's disease (AD) and ARCD.

High MUFA intake per se appears to be associated with the preservation of cognitive functions in healthy elderly people. This effect could be related to the role of fatty acids in maintaining the structural integrity of neuronal membranes. In fact, the factors that modify neuronal membrane fluidity are dietary fatty acids, in particular polyunsaturated fatty acids (PUFA). PUFA may determine the fluidity of synaptosomal membranes and thereby regulate neuronal transmission ${ }^{30}$. A recent study examined the influence of the $n-6 / n-3$ fatty acids ratio on oxidative enzymes ${ }^{31}$. Furthermore, essential fatty acids can modify the function of the neurotransmitters' receptors such as cholinergic receptors, nicotinic receptors, adrenergic receptors, dopaminergic receptors, muscarinic receptors and $N$-methyl-D-aspartate receptors. Finally, free fatty acids, lipid metabolites and phospholipids modify the function of membrane proteins, including ion channels. In fact, a few studies have examined the effects of essential fatty acids on membrane function as they can affect the calcium, chloride and potassium ion channels ${ }^{32}$. A recent study on the fatty acid composition of neuronal membranes demonstrated an increase in MUFA content 
and a decrease in PUFA content with advancing age ${ }^{33}$. It seems that, in the ageing process, there is an increasing demand of unsaturated fatty acids. In fact, in lymphocytic and macrophage-like cells, an increase of $\Delta^{9}$ desaturase activity, which converts stearic acid to oleic acid and increases the degree of differentiation of cells, has been observed $^{34}$. These findings are consistent with another recent study in which high PUFA intake was positively associated with cognitive impairment, while high fish consumption tended to be inversely associated with cognitive impairment ${ }^{35}$.

\section{Role of dietary macronutrients in vascular dementia}

In contrast to ARCD, a diagnosis of dementia is made when cognitive impairment is greater than that found in normal ageing, affects two or more cognitive domains, and affects the person's ability to function ${ }^{4,36}$. Several studies have extensively investigated the causes of dementia, both primary degenerative dementia (AD) and vascular dementia (VaD). Vascular factors, particularly stroke and hypertension, probably play a role in about half of all cases of dementia (including $\mathrm{VaD}$ and mixed dementias, i.e. degenerative forms with vascular components). In fact, vascular-related dementias may be the most common type of dementia in the very old ${ }^{37,38}$. Risk factors for vascular cognitive decline, stroke and coronary artery disease are most likely the same ${ }^{38,40}$. Vascular risk factors include atherosclerosis, hypertension, obesity, transient ischaemic attacks, carotid stenosis, diabetes mellitus, alcohol abuse, antiphospholipid antibody syndrome, hyperviscosity, elevated fibrinogen and cigarette smoking. Frequently, several risk factors coexist in the same individual and interact with one another. The protective effect of some dietary micronutrients with antioxidant properties seems to be better defined in VaD than in $\mathrm{AD}^{41,42}$. Low dietary salt intake improves hypertension. In addition, dietary restriction of cholesterol, fats and calories is important for dyslipoproteinaemia, obesity and diabetes mellitus. A prospective 12-year follow-up study of 859 healthy subjects aged $50-79$ years provided some preliminary evidence that dietary potassium may be vasoprotective; there was a $40 \%$ reduction in stroke mortality with a $10 \mathrm{mmol} \mathrm{day}^{-1}$ increase in dietary potassium intake ${ }^{43}$.

One of the most interesting findings of a recent study on $\mathrm{VaD}$ risk factors conducted on the cohort of the Honolulu Heart Program, within the Honolulu-Asia Aging Study, was the protective effect of a Western diet preference against the development of $\mathrm{VaD}^{44}$. A traditional Western diet is high in animal fat and protein and low in complex carbohydrates compared with the traditional Japanese diet, which is high in complex carbohydrates and low in animal fat and protein. Several lines of evidence suggest the Oriental diet may predispose to stroke. The mechanism by which an Oriental diet leads to VaD remains speculative. The higher risk of stroke could probably be ascribed to the lower intake of animal fat and protein. However, these findings do not allow analysis of separate nutrients. Recent studies have hypothesised that greater fat intake may stabilise the integrity of smaller intracranial arterioles $^{45}$, while the quantity and quality of dietary protein may affect small vessel pathology ${ }^{46}$.

\section{Alzheimer's disease and diet}

Recent findings showing that elderly African Americans ${ }^{47}$ and Japanese living in the $\mathrm{USA}^{48,49}$ have a much higher prevalence of $\mathrm{AD}(6.24 \%$ and $4.1 \%$, respectively) than those still living in their ethnic homelands $(<2 \%)$ suggest that the prevalence of $\mathrm{AD}$ is more strongly influenced by diet and nutrition, environment and/or lifestyle than by genetics. Recent papers linking clinical expression of $\mathrm{AD}$ to oxidative stress ${ }^{50,51}$ and cerebral infarct indicate that the clinical expression of $\mathrm{AD}$ is facilitated by cerebral infarction or stroke, and suggest that diet is a key factor in the development of $\mathrm{AD}^{52,53}$. In a recent study, regression analyses were performed on the prevalence of $\mathrm{AD}$ in the population aged $65+$ of 11 countries obtained from 18 community-wide studies versus components of the national diets ${ }^{54}$. The primary findings are that the contributions of fat and total calories have the highest correlations with $\mathrm{AD}$ prevalence rates. In addition, fish consumption is found to reduce the prevalence of AD in European and North American countries. Recent findings that several dietary components and supplements have been found effective in delaying the onset of $\mathrm{AD}$, including antioxidants, fish and non-steroidal antiinflammatory drugs, are consistent with these data. This preliminary evidence is in agreement with the findings of recent epidemiological studies ${ }^{55}$. In fact, the finding that total dietary fat is a high risk factor for the development of $\mathrm{AD}$ has been reported in the Rotterdam Study, although not at a statistically significant level. In the same study, fish consumption was confirmed to reduce $\mathrm{AD}$ risk and linoleic acid was inversely correlated with $\mathrm{AD}^{56}$. A significant inverse correlation was found between the fraction of calories derived from cereals and $\mathrm{AD}$ prevalence ${ }^{55}$. While whole grains have antioxidant vitamins and minerals, it is not clear whether the cereals generally consumed are whole grains. The inverse correlation is likely to arise from the fact that countries with low fat supply have high cereals supply, rather than any direct therapeutic effect of the cereals. This point should be investigated in greater depth. Finally, red wine - another component of the Mediterranean diet - was investigated in the PAQUID study. Here, the relative risk of dementia was 0.21 and of $\mathrm{AD} 0.25$ among the 318 subjects of this cohort who drank three or four glasses of wine each day, compared with a relative risk of 1 in the 971 total abstainers. Among the 922 older subjects who drank no 
more than one or two glasses of wine each day, the relative risk for $\mathrm{AD}$ was significantly reduced $(0.55)^{57}$.

\section{Summary}

In conclusion, the Mediterranean diet pattern based on complex carbohydrates, fibre and non-animal fat appears to protect against ARCD and cognitive decline of vascular or degenerative origin. However, a clear reduction of ARCD risk has been found only in population samples with high intakes of MUFA from olive oil $\left(>2400 \mathrm{~kJ} \mathrm{day}^{-1}\right.$, corresponding to $>100 \mathrm{~g}$ of olive oil per day). Whether this protective effect of olive oil is attributable exclusively to the high MUFA intake or to the concomitant presence of antioxidant compounds (tocopherol and polyphenols) remains to be elucidated.

\section{Acknowledgements}

This study was supported by the Italian Longitudinal Study on Aging (Italian National Research Council (CNR)Targeted Project on Aging, grant numbers 9400419PF 40 and 95973PF40), by the Targeted Project on Mediterranean Diet (CNR) and by the Italian Ministry of University and Scientific and Technological Research (MURST), 40\% and $60 \%$. V.S. and A.D. participated in the PhD project 'Carcinogenesis, aging, and immunoregulation' supported by the European Union. The authors thank Dr Giovanni Castellaneta for skilful assistance.

\section{References}

1 Crook T, Bartus RT, Ferris SH, Whitehouse PJ, Cohen GD, Hershon S. Age-associated memory impairment: proposed diagnostic criteria and measures of clinical change - report of a National Institute of Mental Health work group. Developmental Neuropsychology 1986; 2: 261-76.

2 Hanninen T, Hallikainen M, Koivisto K, Helkala EL, Reinikainen KJ, Soininen $\mathrm{H}$, et al. A follow-up study of age-associated memory impairment: neuropsychological predictors of dementia. Journal of the American Geriatrics Society 1995; 43: 1007-15.

3 Ritchie K, Leibovici D, Ledesert B, Touchon J. A typology of sub-clinical senescent cognitive disorder. British Journal of Psychiatry 1996; 168: 470-6.

4 American Psychiatric Association, Committee on Nomenclature and Statistics. Diagnostic and Statistical Manual of Mental Disorders, 4th ed. (DSM-IV). Washington, DC: American Psychiatric Association, 1994.

5 Levy R. Aging-associated cognitive decline. Working Party of the International Psychogeriatric Association in collaboration with the World Health Organization. International Psychogeriatrics 1994; 6: 63-8.

6 Brayne C, Calloway P. Normal ageing, impaired cognitive function and senile dementia of Alzheimer type: a continuum? Lancet 1988; 1: 1265-7.

7 Paykel ES, Brayne C, Huppert FA, Gill C, Barkley C, Gehlhaar $\mathrm{E}$, et al. Incidence of dementia in a population older than 75 years in the United Kingdom. Archives of General Psychiatry 1994; 51: 325-32.

8 Roth M, Tym E, Mountjoy CQ, Huppert FA, Hendrie H, Verma S, et al. CAMDEX. A standardised instrument for the diagnosis of mental disorders in the elderly with special reference to the early detection of dementia. British Journal of Psychiatry 1986; 149: 698-709.

9 Nolan KA, Blass JP. Preventing cognitive decline. Clinics in Geriatric Medicine 1992; 8: 19-34.

10 Fillit HM. The clinical significance of normal cognitive decline in late life. In: Fillit HM, Butler RN, eds. Cognitive Decline. Strategies for Prevention. Oxford: Oxford University Press, 1997; $1-7$.

11 Breteler MM, Claus JJ, Grobbee DE, Hofman A. Cardiovascular disease and distribution of cognitive function in elderly people: the Rotterdam Study. British Medical Journal 1994; 308: $1604-8$.

12 Launer LJ, Masaki K, Petrovich H, Foley D, Havlik RJ. The association between midlife blood pressure levels and latelife cognitive function. Journal of the American Medical Association 1995; 274: 1846-51.

13 Richardson JT. Cognitive function in diabetes mellitus. Neuroscience and Biobehavioral Reviews 1990; 14: 385-8.

14 Blazer D, Burchett B, Service C, George LK. The association of age and depression among the elderly: an epidemiologic exploration. Journal of Gerontology 1991; 46: M210-5.

15 Rogers RL, Meyer JS, Mortal KF. After reaching retirement age, physical activity sustains cerebral perfusion and cognition. Journal of the American Geriatrics Society 1990; 38: $123-8$.

16 White LR, Foley DJ, Havlik RJ. Lifestyle risk factors for cognitive impairment. In: Fillit HM, Butler RN, eds. Cognitive Decline. Strategies for Prevention. Oxford: Oxford University Press, 1997; 23-32.

17 Sahyoun NR, Otradovec CL, Hartz SC, Jacob RA, Peters H, Russell RM, et al. Dietary intakes and biochemical indicators of nutritional status in an elderly, institutionalized population. American Journal of Clinical Nutrition 1988; 47 : 524-33.

18 Goodwin J, Goodwin J, Garry P. Association between nutritional status and cognitive functioning in a healthy elderly population. Journal of the American Medical Association 1983; 249: 2917-21.

19 Siebens H, Trupe E, Siebens A, Cook F, Anshen S, Hanauer R, et al. Correlates and consequences of eating dependency in institutionalized elderly. Journal of the American Geriatrics Society 1986; 34: 192-8.

20 Willett WC, Sacks F, Trichopoulou A, Drescher G, FerroLuzzi A, Helsing E, et al. The Mediterranean diet pyramid: a cultural model for healthy eating. American Journal of Clinical Nutrition 1995; 61(Suppl.): 1402S-6S.

21 Capurso A, Solfrizzi V, Panza F, Tores F, Mastroianni F, Grassi A, et al. Dietary patterns and cognitive functions in elderly subjects. Aging Clinical and Experimental Research 1997; 9(Suppl. 4): 45-7.

22 Solfrizzi V, Panza F, Torres F, Mastoianni F, Del Parigi A, Venezia A, et al. High monounsaturated fatty acids intake protects against age-related cognitive decline. Neurology 1999; 52: 1563-9.

23 Solfrizzi V, Panza F, Capurso A. The role of diet in cognitive decline. Journal of Neural Transmission 2003; 110: 95-110.

24 La Rue A, Koehler KM, Wayne SJ, Chiulli SJ, Haadland KY, Garry PJ. Nutritional status and cognitive functioning in a normally aging sample: a 6-y reassessment. American Journal of Clinical Nutrition 1997; 65: 20-9.

25 Pradignac A, Schlienger JL, Velten M, Mejean L. Relationships between macronutrient intake, handicaps, and cognitive impairments in free living elderly people. Aging Clinical and Experimental Research 1995; 7: 67-74.

26 Ortega RM, Requejo AM, Andres P, Lopez-Sobaler AM, Quintas ME, Redondo MR, et al. Dietary intake and cognitive function in a group of elderly people. American Journal of Clinical Nutrition 1997; 66: 803-9.

27 Manna C, Galletti P, Cucciolla V, Moltedo O, Leone A, 
Zappia V. The protective effect of the olive oil polyphenol (3,4-dihydroxyphenyl)-ethanol counteract reactive oxygen metabolite-induced cytotoxicity in Caco- 2 cells. Journal of Nutrition 1997; 127: 286-92.

28 Mittenberg W, Seidenberg M, O'Leary DS, DiGiulio DV. Changes in cerebral functioning associated with normal aging. Journal of Clinical and Experimental Neuropsychology 1989; 11: 918-32.

29 Jama JW, Launer LJ, Witteman JC, den Breeijen JH, Breteler $\mathrm{MM}$, Grobbee DE, et al. Dietary antioxidants and cognitive function in a population-based sample of older persons. The Rotterdam Study. American Journal of Epidemiology 1996; 144: $275-80$.

30 Jones CB, Arai T, Rapoport SI. Evidence for the involvement of docosahexanoic acid in cholinergic stimulated signal transduction at the synapse. Neurochemical Research 1997; 22: $663-70$.

31 Yehuda S, Rabinovitz S, Mostofsky DI. Essential fatty acids preparation (SR-3) on brain biochemistry and on behavioral and cognitive functions. In: Yehuda S, Mostofsky DI, eds. Handbook of Essential Fatty Acids Biology: Biochemistry, Physiology, and Behavioral Neurobiology. Totowa, NJ: Humana Press, 1997; 427-52.

32 Yehuda S, Rabinovitz S, Mostofsky DI. Essential fatty acids are mediators of brain biochemistry and cognitive functions. Journal of Neuroscience Research 1999; 56: 565-70.

33 Lopez GH, Ilincheta de Boschero MG, Castagnet PI, Giusto NM. Age-associated changes in the content and fatty acids composition of brain glycerophospholipids. Comparative Biochemistry and Physiology. Part B, Biochemistry \& Molecular Biology 1995; 112: 331-43.

34 Marzo I, Martinez-Lorenzo MJ, Anel A, Desportes P, Alava MA, Naval J, et al. Biosynthesis of unsaturated fatty acids in the main cell lineages of human leukemia and lymphoma. Biochimica et Biophysica Acta 1995; 1257: 140-8.

35 Kalmijn S, Feskens EJ, Launer LJ, Kromhout D. Polyunsaturated fatty acids, antioxidants, and cognitive functions in very old men. American Journal of Epidemiology 1997; 145: $33-41$.

36 McKhann G, Drachman D, Folstein M, Katzman R, Price D, Stadham EM. Clinical diagnosis of Alzheimer's disease: report of the NINCDS-ADRDA Work Group under the auspices of Department of Health and Human Services Task Force on Alzheimer's Disease. Neurology 1984; 34: 939-44.

37 White L. Is silent cerebrovascular disease an important cause of late-life cognitive decline? Journal of the American Geriatrics Society 1996; 44: 328-30.

38 Larson EB. Illnesses causing dementia in the very elderly. New England Journal of Medicine 1993; 328: 203-5.

39 Erkinjutti T, Hachinski V. Rethinking vascular dementia. Cerebrovascular Diseases 1993; 3: 3-23.

40 Gorelick PB, Mangone CA. Vascular dementia in the elderly. Clinics in Geriatric Medicine 1991; 7: 599-615.

41 Gey KF, Stahelin HB, Eicholzer M. Poor plasma status of carotene and vitamin $\mathrm{C}$ is associated with higher mortality from ischemic heart disease and stroke. Clinical Investigator 1993; 71: 3-6.

42 White BC, Grossman LI, Krause GS. Brain injury by global ischemia and reperfusion: a theoretical perspective on membrane damage and repair. Neurology 1993; 43: $1656-65$.

43 Khaw KT, Barret-Connor E. Dietary potassium and stroke associated mortality. A 12-year prospective population study. New England Journal of Medicine 1987; 316: 235-40.

44 Ross GW, Petrovich H, White LR, Masaki KH, Li CY, Curb JD, et al. Characterization of risk factors for vascular dementia. The Honolulu-Asia Aging Study. Neurology 1999; 53: $337-43$.

45 Gillman MW, Cupples LA, Millen BE, Ellison RC, Wolf PA. Inverse association of dietary fat with the development of ischemic stroke. Journal of the American Medical Association 1997; 278: 2145-50.

46 Yamori Y, Horie R, Tanase H, Fujiwara K, Nara Y, Lovenberg $\mathrm{W}$. Possible role of nutritional factors in the incidence of cerebrovascular lesions in stroke-prone spontaneously hypertensive rats. Hypertension 1984; 6: 49-53.

47 Hendrie HC, Osuntokun BO, Hall KS, Ogunniyi AO, Hui SL, Unverzagt FW, et al. Prevalence of Alzheimer's disease and dementia in two communities: Nigerian Africans and African Americans. American Journal of Psychiatry 1995; 152: $1485-92$.

48 Graves AB, Larson EB, Edland SD, Bowen JD, McCormick WC, McCurry SM, et al. Prevalence of dementia and its subtypes in the Japanese American population of King County, Washington State. The Kame Project. American Journal of Epidemiology 1996; 144: 760-71.

49 White L, Petrovitch H, Ross GW, Masaki KH, Abbott RD, Teng EL, et al. Prevalence of dementia in older JapaneseAmerican men in Hawaii: The Honolulu-Asia Aging Study. Journal of the American Medical Association 1996; 276: 955-60.

50 Harman D. Free radical theory of aging: Alzheimer's disease pathogenesis. Age 1995; 18: 97-119.

51 Smith MA, Sayre L, Perry G. Morphological aspects of oxidative damage in Alzheimer's disease. In: Beal MF, Howell H, Bodis-Wollner I, eds. Mitochrondria and Free Radicals in Neurodegenerative Diseases. New York: WileyLiss Inc., 1997; 50.

52 Hulette C, Nochlin D, McKeel D, Morris JC, Mirra SS, Sumi SM, et al. Clinical-neuropathologic findings in multi-infarct dementia: a report of six autopsied cases. Neurology 1997; 48: 668-72.

53 Snowdon DA, Greiner LH, Mortimer JA, Riley KP, Greiner PA, Markesbery WR. Brain infarction and the clinical expression of Alzheimer's disease. The Nun Study. Journal of the American Medical Association 1977; 277: 811-7.

54 Grant B. Dietary links to Alzheimer's disease. Alzheimer's Disease Review 1997; 2: 42-55.

55 Grant B. Dietary links to Alzheimer's disease: 1999 update. Journal of Alzheimer's Disease 1999; 1: 197-201.

56 Kalmijn S, Lauher LJ, Ott A, Witteman JC, Hofman A, Breteler MM. Dietary fat intake and the risk of incident dementia in the Rotterdam Study. Annals of Neurology 1997; 42: 776-82.

57 Orgogozo JM, Dartigues JF, Lafont S, Letenneur L, Commenges D, Salamon R, et al. Wine consumption and the elderly: a prospective community study in the Bordeaux area. Revue Neurologique 1997; 153: 185-92. 